\title{
Optimization of Curing and Extraction Time on Production of Base Gelatin from Bovine Skin Material
}

\author{
Asrul Bahar ${ }^{1}$, Nita Kusumawati ${ }^{2}$, Mirwa Adipraha Anggrani ${ }^{2}$, Supari Muslim ${ }^{3}$ \\ Home Economic Department \\ Chemistry Department ${ }^{2}$ \\ Electrical Engineering Department ${ }^{3}$ \\ Universitas Negeri Surabaya \\ Surabaya, Indonesia \\ asrulbahar@unesa.ac.id
}

\begin{abstract}
To explore gelatin materials used in any purposes for food additive with Indonesian local sources, gelatin in this study was prepared from bovine skin via base method. The effects of curing $(10,30$, and 50 days) and extraction time $(4,5$, and 6 hours) on yield percentage, $\mathrm{pH}$, viscosity, organoleptic properties (odor, taste, and color), water contents, as well as the ash content of its material were invested. The results showed that the bovine gelatin with longer curing time and longer extraction time exhibited biomaterial with higher yield percentage, higher pH, lower viscosity, darker color, higher water and ash content. No obvious differences were detected from physical shape, odor and texture of bovine material that prepared with longer stirring time and longer extraction time. To sum up, the bovine skin gelatin which produced with 30 days curing time and 5 hours extraction time showed better water content, viscosity, and organoleptic properties compared to the others. Despite producing higher ash contents and $\mathrm{pH}$, the manufacturing process with longer curing and extraction time could still be applied considering the water content, viscosity and organoleptic properties as long as meeting the standard of GMIA and (SNI) 06-3735-1995
\end{abstract}

Keywords-Gelatin; Bovine, Skin; Base method.

\section{INTRODUCTION}

Gelatin has been traditionally produced through hydrolysis of collagen from the skin and bones of bovine and porcine by an acidic or alkaline process [1]. It is derived from a partial breakdown of a natural triple helical structure of collagen [2]. Gelatin has been applied to food and non-food industries [3,4] Recently, and especially in the food industry, an increasing number of new applications has been found in many products such as, emulsifiers, foaming agents, colloid stabilizers, biodegradable film-forming materials and microencapsulating agents, in line with the growing trend to replace synthetic agents with more natural ones[5,6]

Despite wide applications, the uses of gelatins are still limited due to the pessimism and strong concerns related to the region [7]. Porcine gelatin cannot be used in Kosher and Halal foods, while poultry gelatin has also become concerns due to avian influenza [8]. That is why there is an urgent need to find an alternative source that can replace the currently available gelatins as an additional option to meet customer needs. Waste by-products from cattle farm industry such as bovine skin and bone may be potential sources to replace porcine sources of gelatin.

Generally, functional properties of gelatin are governed by several factors, such as raw material, pretreatment and extraction conditions $[4,9,12]$. In order to determine the effect of curing and extraction time on the yield and quality of alkaline gelatin produced from bovine skin material, pretreatment was performed with various curing (10-50 days) and extraction time (4-6 hours). This study was aimed to develop halal gelatin production procedure from bovine skin, generated as wastes by the bovine processing industries; and to examine their organoleptic properties as well as water and ash content in relation to porcine gelatin.

The potential development of gelatin industry in Indonesia is actually quite promising. However, up to now there are no small and medium industries which produce gelatin commercially. So, the need for gelatin in Indonesia still completely depends on imported products. In an attempt to reduce the dependence on imported products, the development of gelatin industry in Indonesia is believed to be very potential market share. Anticipating the future development of gelatin industry in Indonesia with the biggest adherents of Islam, it is, of course, necessary to find sources of raw materials which are kosher, hygienic, cheap, large potential, easy to obtain and environmentally friendly. One alternative of raw material which is known to be quite potential is bovine skin material.

\section{MATERIALS AND METHODS}

\section{A. Chemicals}

The bovine skin of local cattle was used as a raw material for the extraction of gelatin. Skins were obtained from Pegirian Slaughterhouse (Surabaya, Indonesia) and brought to the laboratory in insulated containers. They were washed with potable water, cut into small pieces using sharp knives, packed in polyethylene bags and used for the extraction of gelatin. 
Anhydrous calcium oxide $(\mathrm{CaO})$ (powder, $\geq 99.99 \%$ ) for curing and hydrochloride acid $(\mathrm{HCl})$ (reagent grade, $37 \%$ ) were purchased from Sigma-Aldrich (Singapore).

\section{B. Extraction of Gelatin from Bovine Skin}

The bovine skin was firstly treated with $\mathrm{CaO}$ in order to remove non-collagenous proteins. Bovine skin was soaked in $\mathrm{CaO} 10 \%(\mathrm{w} / \mathrm{v})$ for 10 days at room temperature. The alkaline | solution was changed every 2 days._The alkaline-treated skins were then washed with distilled water until neutral $\mathrm{pH}$ was obtained.

Gelatin was extracted according to the method of GMIA (2012). The number of extractions was three times by increasing temperature application. The first extraction was carried out at a temperature of $60^{\circ} \mathrm{C}$, while the second and third extractions, respectively performed at temperatures of $70^{\circ} \mathrm{C}$ and $100^{\circ} \mathrm{C}$. All process of extractions, first to third, was done for 4 hours. The extracts were then filtered using two layers of fabric and stored separately, for various analyzes required.

To determine the effect of curing and extraction time on the yield and quality of gelatin produced from bovine skin material, the curing process was carried out at various times including 10 days, 30 days and 50 days. In line with this, the extraction process was also done with diverse time, covering 4 hours, 5 hours, and 6 hours.

\section{Analysis of Gelatin}

\section{- Proximate Analysis}

The water and ash content of the gelatin powder were determined according to the AOAC method number 927.05 and 942.05, respectively (AOAC, 2000).

The gelatin yield was calculated based on wet weight of fresh skin.

$$
\text { Rendement }(\%)=\frac{\text { Weight of dried gelatin }(g)}{\text { Weight of fresh goat skin }} \times 100
$$

\section{- Determination of $p H$}

The acidity of the halal gelatin $(6.67 \mathrm{~g} / 100 \mathrm{ml}$ dissolved at $60^{\circ} \mathrm{C}$ ) was measured using a bench meter (ECION51041S; Eutech Instruments, Malaysia).

\section{- Determination of $p H$}

The viscosity of the halal gelatin $(6.67 \mathrm{~g} / 100 \mathrm{ml}$ dissolved at $60^{\circ} \mathrm{C}$ ) was measured using a Visco meter (Minolta CM-3500D; Minolta Co. Ltd., Osaka, Japan).

\section{- Determination of Gelatin Gel Color}

CieLab color values $\left(L^{*}, a^{*}, b^{*}\right)$ of the halal gelatin $\left(6.67 \mathrm{~g} / 100 \mathrm{ml}\right.$ dissolved at $\left.60{ }^{\circ} \mathrm{C}\right)$ were measured using a colorimeter (Minolta CM-3500D; Minolta Co. Ltd., Osaka, Japan) and colour parameters were computerized in a system using Spectra Magic Software version 2.11 (Minolta Cyberchrom Inc.,
Osaka, Japan). In this coordinate system, the $L^{*}$ represents the difference between light $\left(L^{*}=100\right)$ and dark $\left(L^{*}=0\right)$. The component $a^{*}$ represents the difference between green $\left(-a^{*}\right)$ and red $\left(+a^{*}\right)$, component $b^{*}$ represents the difference between blue ($\left.b^{*}\right)$ and yellow $\left(+b^{*}\right)$.

\section{RESUlT AND DiSCUSSION}

\section{A. Proximate Composition}

The results of yield of bovine skin gelatin obtained using different curing and extraction times were reported in Table 1. It can be percieved that the curing and extraction conditions had strong effect on the yield of bovine skin gelatin, in which the yield - significantly increased when the curing and extraction were performed in the longer time. In the other words, the highest yield was obtained for the bovine gelatin which extracted for 50 days of curing time $(24.20 \%$ after 10 days; $26.59 \%$ after 30 days and $29.12 \%$ after 50 days of curing times). The lowest yield was obtained for the bovine skin gelatin which extracted at 10 days of curing time. Meanwhile, the moderate yield was obtained for the bovine skin gelatin which extracted at 30 days of curing time $(26.59 \%$ after $4 \mathrm{~h}$; $27.74 \%$ after $5 \mathrm{~h}$ and $29.50 \%$ after 6 days of extraction times). The base curing material broke the peptide bonding molecules on the right chains to the optimum level. So, the results tended to increase concentration of $10 \%$ curing material. The yield of gelatin produced in the production process depended on the process performed on collagen protein. The highest yield was obtained at base curing process at $10 \%$ concentration of curing solution with 50 days of curing time.

Increased bovine skin gelatin yield was also detected along with the increase in extraction time applied. Increased extraction time will lead to the optimum process of collagen protein extraction from the bovine skin material, which will then hydrolyze into gelatin in water. The highest yield was obtained at the base process at $10 \%$ concentration with 6 hours extraction time.

TABLE I. YIELD OF BOVINE SKIN GELATIN PRODUCED WITH DIFFERENT CURING AND EXTRACTION TIME

\begin{tabular}{|c|c|c|c|}
\hline \multirow{2}{*}{ Type } & \multicolumn{2}{|c|}{ Processing Time } & \multirow{2}{*}{ Yield (\%) } \\
\cline { 2 - 3 } & $\begin{array}{c}\text { Curing } \\
\text { (days) }\end{array}$ & $\begin{array}{c}\text { Extraction } \\
\text { (hours) }\end{array}$ & \\
\hline BSG-1 & 10 & 4 & 24.20 \\
\hline BSG-2 & 30 & 4 & 26.59 \\
\hline BSG-3 & 50 & 4 & 29.12 \\
\hline BSG-4 & 30 & 5 & 27.74 \\
\hline BSG-5 & 30 & 6 & 29.50 \\
\hline
\end{tabular}

The results of proximate composition of bovine skin gelatin obtained using different curing and extraction times were reported in Table 2. It can be percieved that the curing and extraction conditions had a strong effect on the water content of bovine skin gelatin, in which the water content significantly decreased when the curing and extraction were done in the shorter time. In the other words, the lowest water content was obtained for the bovine gelatin extracted at curing 
time 10 days (5\% after $4 \mathrm{~h}$ extraction times). The highest water content was obtained by the bovine skin gelatin which extracted at 50 days of curing time $(10 \%$ after $4 \mathrm{~h}$ extraction times). Meanwhile, the water content of the bovine skin gelatin which produced by 30 days curing times was $5 \%$ after $4 \mathrm{~h}$ extraction time, and $10 \%$ for both, gelatin produced from $5 \mathrm{~h}$ and $6 \mathrm{~h}$ extraction times. This is probably due to the optimum time of adsorption of the curing solution into the bovine skin material in order to decipher the triple helix structure of collagen proteins. High levels of water entering into the skin material to a certain depth had inhibited the release of water in the drying process of gelatin and leaving a high water content in the obtained gelatin product.

In line with this, the longer extraction time applied to the process of bovine skin gelatin production had optimized the process of water molecules adsorption by the skin material. The condition will cause the longer heating time required in the gelatin drying process. In this condition, it is not recommended to use high temperature in gelatin drying process. Application of high temperatures will trigger the occurrence of face hardening event in the form of very dry layer on the surface of the material so that it will inhibit the process of further evaporation of water molecules from the inside of the material. The lowest water content was obtained at the base process at $10 \%$ concentration with 10 days curing and 4 hours extraction time. The value of gelatin water content produced is still in accordance with the required standards, by SNI with the maximum value of $16 \%$.

In line to the results of the water content analysis showing an increase in water content, ash content analysis showed an increase in ash content along with increased curing and extraction time on the base gelatin production process from the bovine skin material. Table 3 shows an increase in the ash content of gelatin products as curing and extraction time increases. Determination of ash content is one way to know the purity of a material. Ash is an inorganic residue from the burning of organic materials.

TABLE II. WATER CONTENT OF BOVINE SKIN GELATIN PRODUCED WITH DIFFERENT CURING AND EXTRACTION TIME

\begin{tabular}{|c|c|c|c|}
\hline \multirow{2}{*}{ Type } & \multicolumn{2}{|c|}{ Processing Time } & Water Content \\
\cline { 2 - 3 } & $\begin{array}{c}\text { Curing } \\
\text { (days) }\end{array}$ & $\begin{array}{c}\text { Extraction } \\
\text { (hours) }\end{array}$ & 5 \\
\hline BSG-1 & 10 & 4 & 5 \\
\hline BSG-2 & 30 & 4 & 10 \\
\hline BSG-3 & 50 & 4 & 10 \\
\hline BSG-4 & 30 & 5 & 10 \\
\hline BSG-5 & 30 & 6 & \\
\hline
\end{tabular}

Increased curing time or base treatment will optimize the solubility of minerals from the bovine skin material to produce a gelatin product with minimum ash content. On the other hand, increasing curing time will provide a longer opportunity for the adsorption of curing solution into the bovine skin material layer, thereby complicating the neutralization process by the washing method. Ineffective bovine skin washing process after a longer curing process has induced the deposition of the curing particles in bovine skin material. This condition will cause the existence of high levels of mineral in the gelatin solution obtained from the extraction with increasing temperature. The extraction process with a relatively high temperature over a long period of time will further increase the mineral solubility potential from the bovine skin material. This also causes an increase in ash content of bovine skin gelatin products obtained along with the increasing time of extraction applied at each stage. Therefore, it is important to optimize the process of neutralization of bovine skin material after going through the curing stage in a specific time period.

TABLE III. ASH CONTENT OF BOVINE SKIN GELATIN PRODUCED WITH DIFFERENT CURING AND EXTRACTION TIME

\begin{tabular}{|c|c|c|c|}
\hline \multirow{2}{*}{ Type } & \multicolumn{2}{|c|}{ Processing Time } & \multirow{2}{*}{ Ash Content (\%) } \\
\cline { 2 - 3 } & $\begin{array}{c}\text { Curing } \\
\text { (days) }\end{array}$ & $\begin{array}{c}\text { Extraction } \\
\text { (hours) }\end{array}$ & \\
\hline BSG-1 & 10 & 4 & 3.30 \\
\hline BSG-2 & 30 & 4 & 3.98 \\
\hline BSG-3 & 50 & 4 & 5.97 \\
\hline BSG-4 & 30 & 5 & 5.54 \\
\hline BSG-5 & 30 & 6 & 8.28 \\
\hline
\end{tabular}

The result value of gelatin ash content in this research was above the standard required by SNI with a maximum value of $3.25 \%$. The higher ash content in all gelatin samples indicated the presence of inorganic salts, which might be generated during the pretreatment with either alkali or acid. We notice that BSG-1 had the lowest ash $(3.30 \%)$ and was closest to the ash content standard set by SNI.

\section{B. $p H$ Value}

One of the important chemical properties of gelatin is the degree of acidity $(\mathrm{pH})$ as it related to other properties such as the ability to bind with water, viscosity and emulsion capacity. Table 4 shows the $\mathrm{pH}$ value of bovine skin gelatin products with varying curing and extraction times.

Results of $\mathrm{pH}$ analysis of bovine skin gelatin products, as shown in Table 4, show an increase in gelatin $\mathrm{pH}$ as curing and extraction time increases. Increased curing time during pre-treatment of bovine skin gelatin has optimized the adsorption of curing solution into bovine skin material. The high quantity of curing solution adsorbed into bovine skin material had impeded the neutralization stage prior to the extraction process. This led to the detection of an increase in the $\mathrm{pH}$ of bovine skin gelatin products as curing time increases during the pre-treatment process

TABLE IV. PH VALUES OF GELATINS FROM THE BOVINE SKIN IN COMPARISON WITH COMMERCIAL BOVINE GELATIN

\begin{tabular}{|c|c|}
\hline Type & pH \\
\hline BSG-1 & 8.51 \\
\hline BSG-2 & 8.70 \\
\hline BSG-3 & 8.90 \\
\hline BSG-4 & 8.79 \\
\hline BSG-5 & 8.94 \\
\hline
\end{tabular}

In parallel, the application of extraction times with relatively high temperatures over a long period of time had permitted the dissolving of the absorption, in which in this case was the curing solution, from within the bovine skin 
material. Thus, increasing the extraction time will have a direct impact on the increase of gelatin $\mathrm{pH}$ obtained.

The $\mathrm{pH}$ value of bovine skin gelatin produced by alkaline processes by increasing curing and extraction time in this study was still above the $\mathrm{pH}$ value standard of gelatin set by GMIA, namely 5.0-7.5.

\section{Viscosity}

Viscosity is the holding ability of a liquid to flow. The flow process of a liquid is influenced by viscosity due to adsorption and colloidal development [13]. Table 5 shows the viscosity of bovine skin gelatin products with varying curing and extraction times.

TABLE V. VISCOSITY OF GELATINS FROM THE BOVINE SKIN IN COMPARISON WITH COMMERCIAL BOVINE GELATIN

\begin{tabular}{|c|c|}
\hline Type & Viscosity (mps) \\
\hline BSG-1 & 23.3 \\
\hline BSG-2 & 22.7 \\
\hline BSG-3 & 21.3 \\
\hline BSG-4 & 27.5 \\
\hline BSG-5 & 11.4 \\
\hline
\end{tabular}

Differences in curing and extraction times have a significant effect on gelatin viscosity. Increased viscosity values are influenced by the structure of amino acid molecules that make up gelatin proteins. Increasingly long chain of amino acids will increase the viscosity value of gelatin. Increased curing time in the pre-treatment process can decrease viscosity. This is because the optimum process of decomposing amino acid peptide bonds by curing solution into a very short chain of molecules along with increasing curing time. The condition has triggered a decrease in viscosity.

In contrast to the effect given by curing time, increasing the extraction time has increased the collagen compound gain which is then hydrolyzed to gelatin from the extraction process performed. The increase in particle content of the gelatin compound has increased the particle density level in the gelatin solution and induced the increased viscosity of the gelatin solution. However, the application of relatively hightemperature applications in longer-term extraction processes, in this case was for 6 hours which resulted in a decrease in the viscosity value of bovine skin gelatin products produced. Based on the data in Table 5, it appears that the viscosity value of gelatin produced from alkaline processes with increasing curing time and extraction was not much different from the value of commercial gelatin viscosity as well as the standard viscosity value required for the base process by GMIA ie 20$75 \mathrm{mps}$. The highest viscosity value was obtained at base process at concentration of $10 \%$ with curing time for 30 days and extraction for 5 hours.

\section{Organoleptic Characteristics}

The characterization result of organoleptic properties in general (color, physical shape, odor, and texture) of gelatin product results showed that descriptively gelatin product produced by an alkaline process with increasing curing time and extraction showed no significant difference.
TABLE VI ORGANOLEPTIC CHARACTERISTICS OF BOVINE SKIN GELATIN PRODUCED THROUGH ALKALINE PROCESSES WITH VARIOUS CURING AND EXTRACTION TIMES

\begin{tabular}{|c|c|c|c|c|c|}
\hline \multirow[b]{2}{*}{$\begin{array}{c}\text { Product } \\
\text { Characterization }\end{array}$} & \multicolumn{5}{|c|}{ Identification Result } \\
\hline & $\begin{array}{l}\vec{b} \\
\text { صి }\end{array}$ & $\begin{array}{l}\tilde{y} \\
\text { ஸे } \\
\tilde{n}\end{array}$ & $\hat{b}$ & 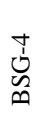 & $\begin{array}{l}n \\
b \\
n \\
n\end{array}$ \\
\hline Color & $\mathrm{a}$ & $\mathrm{b}$ & $\mathrm{b}$ & $\mathrm{b}$ & $\mathrm{b}$ \\
\hline Physical Shape & $\mathrm{c}$ & $\mathrm{c}$ & $\mathrm{c}$ & $\mathrm{c}$ & $\mathrm{c}$ \\
\hline Odor & $\mathrm{e}$ & $\mathrm{e}$ & $\mathrm{e}$ & $\mathrm{e}$ & $\mathrm{e}$ \\
\hline Texture & $\mathrm{f}$ & $\mathrm{f}$ & $\mathrm{f}$ & $\mathrm{f}$ & $\mathrm{f}$ \\
\hline \begin{tabular}{ll}
\multicolumn{2}{l}{ Note : } \\
1. & Brighter (a); \\
2. & Sheet-powde \\
3. & Strong $(d) ; w$ \\
4. & Smooth \& ho
\end{tabular} & $\begin{array}{l}\text { roth } \\
\text { (f) }\end{array}$ & ugh & hot $\mathrm{h}$ & ogen & $s(g)$ \\
\hline
\end{tabular}

Based on the data in Table 6 it appears that the appearance of gelatin product colors generated through alkaline processes with increasing curing time is noticeably darker. The darker gelatin color was obtained from the extraction process with the longer time. Differences in the color display can be caused by the influence of raw materials and production processes [14]. The results of color identification were also not much different from the quality standard required by SNI 06-3735-1995 namely not colored to yellow transparent.

The result of gelatin color characterization with Chroma meter based on the full "L", "a" and "b" color notation are presented in Table 7 . In this coordinate system, the $L^{*}$ represents the difference between light $\left(L^{*}=100\right)$ and dark $\left(L^{*}=0\right)$. The component $a^{*}$ represents the difference between green $\left(-a^{*}\right)$ and red $\left(+a^{*}\right)$, component $b^{*}$ represents the difference between blue $\left(-b^{*}\right)$ and yellow $\left(+b^{*}\right)$.

TABLE VII. COLOR VALUES OF GELATINS FROM THE BOVINE SKIN IN COMPARISON WITH COMMERCIAL BOVINE GELATIN

\begin{tabular}{|c|c|c|c|}
\hline \multirow{2}{*}{ Type } & \multicolumn{3}{|c|}{ Color } \\
\cline { 2 - 4 } & $\mathbf{L}^{*}$ & $\mathbf{a}^{*}$ & $\mathbf{b}^{*}$ \\
\hline BSG-1 & 91.03 & 0.56 & 2.08 \\
\hline BSG-2 & 90.08 & -0.36 & -0.15 \\
\hline BSG-3 & 83.56 & 0.62 & -0.23 \\
\hline BSG-4 & 98.94 & 0.07 & 0.04 \\
\hline BSG-5 & 89.00 & -0.13 & -0.74 \\
\hline
\end{tabular}

BSG-4 shows the greatest lightness value ( $\left.\mathrm{L}^{*}\right)$ compared with BSG-1, BSG-2 and BSG-5. The a* value of gelatin with varying curing and extraction times indicates more dominant red color in the produced gelatin product, while the " $b$ " value of fifth gelatins exhibits more dominant blue color in the gelatin products produced. It can be concluded that manufacture factors such as curing and extraction time influence the color characteristics of extracted gelatin. Both color and clarity of a gelatin gel are important aesthetic properties, depending on the application for which the gelatin 
is intended. Meanwhile, the color did not affect the functional properties of gelatin [15].

\section{CONCLUSION}

Gelatin produced from the bovine skin through alkaline processes with various curing and extraction times has characteristics which have met the water content and viscosity value as well as organoleptic properties specified by GMIA and (SNI) 06-3735-1995. Gelatin produced from bovine skin using $\mathrm{CaO}$ curing solution with a concentration of $10 \%(\mathrm{w} / \mathrm{v})$, 30 days curing time and 5 hours extraction showed the optimum qualitative and quantitative characteristics.

\section{ACKNOWLEDGMENTS}

Acknowledgments of the authors convey to Directorate of Research and Community Service Ministry of Research and Technology of Higher Education Republic of Indonesia for financial support through Superior Research Programs of Higher Education 2017, and to Institute for Research and Community Service Universitas Negeri Surabaya.

\section{REFERENCES}

[1] S. Shakila, P.S. Reddy, P.V.V.S. Reddy, J.V. Ramana, A. Ravi, "Effect of palm kernel meal on the performance of broilers", J. Veterinary \& Animal Sciences, vol. 8(4), pp. 227-234, 2012.

[2] M.E. Han, B.J. Kang, S.H. Kim, H.D. Kim, N.S. Hwang, "Gelatin-based extracellular matrix cryogels for cartilage tissue engineering", Journal of Industrial and Engineering Chemistry, vol. 45, pp. 421-429, 2017.

[3] S. Sinthusamran, S. Benjakul, H. Kishimura, "Characteristics and gel properties of gelatin from a skin of seabass (Lates calcarifer) as influenced by extraction conditions". Food Chemistry, vol. 152(2), pp. 276-284, 2014.

[4] S. Mad-Ali, S. Benjakul, T. Prodpran, S. Maqsood, "Interfacial properties of gelatin from goat skin as influenced by drying methods", LWT Food Sci. Tech. vol. 73, pp. 102-107, 2016.
[5] J. Gomez-Estaca, M.C. Gomez-Guillen, F. Fernandez-Martin, P. Montero, "Effects of gelatin origin, bovine-hide and tuna-skin, on the properties of compound gelatin-chitosan films", Food Hydrocolloids, vol. 25, pp. 1461-1469, 2011.

[6] I. Lassoued, M. Jridi, R. Nasri, A. Dammak, M. Hajji, M. Nasri, A. Barkia, "Characteristics and functional properties of gelatin from thornback ray skin obtained by a pepsin-aided process in comparison with commercial halal bovine gelatin", Food Hydrocolloids, vol. 41, pp. 309-318, 2014.

[7] D.M. Asher, "The transmissible spongiform encephalopathy agents: concerns and responses of United States regulatory agencies in maintaining the safety of biologics", Development in Biological Standardization, vol. 100, pp. 103-118, 1999.

[8] P. Kaewruang, S. Benjakul, T. Prodpran, A.B. Encarnacion, S. Nalinanon, "Impact of divalent salts and bovine gelatin on gel properties of phosphorylated gelatin from the skin of unicorn leatherjacket", LWTFood Science and Technology, vol. 55(2), pp. 477-482, · March 2014

[9] S. Benjakul, P. Kittiphattanabawon, J.M. Regenstein, Fish. B.K. Simpson, L.M.L Nollet, F. Toldrae (Eds.), Food biochemistry and food processing. Ames: John Wiley \& Sons, Inc, 2012.

[10] I. Kolodziejska, K. Kaczorowski, B. Piotrowska, M. Sadowska, "Modification of the properties of gelatin from skins of Baltic cod (Gadus morhua) with transglutaminase", Food Chemistry, vol. 86, pp. 203-209, 2004.

[11] M. Nagarajan, S. Benjakul, T. Prodpran, P. Songtipya, H. Kishimura, "Effects of bleaching on characteristics and functional properties of gelatin from splendid squid (Loligo formosana) skin as affected by extraction temperatures", Food Hydrocolloids, vol. 29, pp. 389-397, 2012.

[12] J.M. Regenstein, P. Zhou, "Collagen and gelatin from marine byproduct". in Maximizing the value of marine by-products, F. Shahidi, Eds. Cambridge: Woodhead Publishing Limited, 2007.

[13] R. Schrieber and H. Gareis, Gelatine Handbook: Theory and Industrial Practice. Ames: John Wiley \& Sons, Inc., 2007).

[14] M. Glicksman, Gum technology in the food industry. New York and London: Academic Press, 1969.

[15] H. W. Ockerman and C. L. Hansen, Animal By-Product Processing \& Utilization. CRC Press, 1969. 